DOI: 10.12731/2070-7568-2019-2-56-71

УДК 658.1

\title{
СИСТЕМА ВНУТРЕННЕГО КОНТРОЛЯ И АУДИТА В СТРАХОВЫХ ОРГАНИЗАЦИЯХ: ПРОБЛЕМЫ И ПЕРСПЕКТИВЫ РАЗВИТИЯ
}

\section{Никитченко Ю.А., Васюкова Л.К.}

В статье исследуются вопросы организации систем внутреннего контроля как формы реализации рисковой функции страхования. Анализируются статистические данные по рынку страховых услуг и обосновываются направления развития системы внутреннего контроля и аудита страховых организаций, её взаимосвязь с государственным финансовым контролем финансовой устойчивости субъектов страхового дела. Рассматривается автоматизированная система внутреннего финансового контроля и аудита, построенная на приниипах риск-ориентированного подхода в соответствии со стандартами Solvency II, как механизм, способствующий достижению локального компромисса в отношениях участников страховых экономических отношений. В ходе проведения исследования был сделан вывод о том, что страховым организациям необходимо внедрение эффективной системы внутреннего контроля, которая позволяла бы органам страхового надзора осуществлять превентивное выявление рисков потери финансовой устойчивости и платежеспособности субъектов страхового надзора.

Цель - разработка модели системы внутреннего контроля и аудита страховых организаций в системе государственного страхового надзора в соответствии с риск-ориентированным подходом.

Метод или методология проведения работы: статья подготовлена на основе проведения кабинетных исследований, информачия собрана посредством качественных методов сбора данных, а именно сравнительного анализа, факторного анализа, формализованного контент-анализа. 
Результаты: разработана модель системы внутреннего контроля и аудита, основанная на принщипах риск-ориентированного надзора в целях ранней диагностики рисков страховых организаций.

Научная новизна исследования - разработка рекомендаций по совершенствованию принципов и методов внутреннего контроля и аудита страховой организации в системе государственного страхового надзора, построенной на принципах риск-ориентированного в изелях превентивной диагностики рисков страховщика.

Область применения результатов: полученные результаты целесообразно применять субъектами страхового надзора, в частности страховыми организациями и органами страхового надзора.

Ключевые слова: внутренний контроль и аудит; страховой pblнок; конфликтно-компромиссная методология; контрольная функциия страхования; риск-ориенторованный подход.

\section{SYSTEM OF INTERNAL CONTROL AND AUDIT IN INSURANCE ORGANIZATIONS: PROBLEMS AND DEVELOPMENT PROSPECTS}

\section{Nikitchenko Ju.A., Vasyukova L.K.}

The article studies the issues of organization of internal control systems as a form of realization of the risk function of insurance. The statistical data on the insurance services market are analyzed and the directions of the development of the internal control and audit system of insurance organizations are substantiated, its relationship with the state financial control of the financial stability of the subjects of the insurance business. We consider an automated system of internal financial control and audit, built on the principles of a risk-oriented approach in accordance with the standards of Solvency II, as a mechanism that facilitates the achievement of a local compromise in the relations of participants in insurance economic relations. In the course of the study, it was concluded that insurance companies need to implement an effective internal control system that would allow the insurance supervisory authorities to 
carry out a preventive identification of risks of loss of financial stability and solvency of insurance supervisors.

Purpose - to develop a model of the system of internal control and audit of insurance companies in the system of state insurance supervision in accordance with the risk-based approach.

Methodology: the article is prepared on the basis of Desk research, information is collected through qualitative methods of data collection, namely comparative analysis, factor analysis, formalized content analysis.

Results: a model of the internal control and audit system based on the principles of risk-based supervision for the early diagnosis of risks of insurance companies.

The scientific novelty of the research is the development of recommendations for improving the principles and methods of internal control and audit of the insurance company in the system of state insurance supervision, based on the principles of risk-oriented for the purpose of preventive risk diagnosis of the insurer.

Practical implications it is advisable to apply the results of the subjects of insurance supervision, in particular insurance companies and insurance supervision bodies.

Keywords: internal control and audit; insurance market; conflict-compromise methodology; control function of insurance; risk-oriented approach.

\section{Введение}

Страхование в настоящее время выступает как эффективный универсальный механизм управления значительной долей рисков граждан и хозяйствующих субъектов. Предпосылкой возникновения и развития страховых экономических отношений являются убытки, возникающие вследствие опасных случайных событий, имеющих различную природу: стихийные бедствия, техногенные аварии, катастрофы, несчастные случаи. По мнению авторитетных экономистов, «нет таких сфер человеческого бытия, которые свободны от случайных опасностей, приносящих человечеству экономические расстройства, и которые в силу этого не нуждались бы в страховании» [7, с. 8]. 
Страхование по своей сущности носит рисковый, вероятностный, случайный характер, отличается сложностью перераспределительных финансовых отношений и наличием обособленных оборотов денежных средств, обеспечивающих страховую защиту и ведение страховой деятельности.

Многогранность финансовых отношений в сфере страхования предполагает создание эффективной системы внутреннего контроля за формированием и использованием финансовых ресурсов страховой организации. При этом внутренний контроль выступает как реализация контрольной функции страхования.

Двойственность стратегии страховщика, противоречивость его стратегических целей порождает управленческую дисфункцию: с одной стороны страховщик, как профессиональный риск-менеджер, принимая на страхование риски других хозяйствующих субъектов, должен быть заинтересован в создании эффективных систем внутреннего контроля рисков страхового портфеля, с целью ранней диагностики вероятности потери финансовой устойчивости и платежеспособности. С другой стороны практика показывает неэффективность существующих систем внутреннего контроля, которые позволяли бы органам страхового надзора осуществлять превентивное выявление рисков потери финансовой устойчивости и платежеспособности субъектов страхового надзора.

Внутреннему контролю и аудиту в страховой организации не уделяется должного внимания, поскольку до сих пор не определено его место в системе управления собственными рисками страховой организации, отсутствует единообразное понимание внутреннего контроля, не сформирована система внутреннего контроля и аудита в страховой организации. В этой связи актуальными становятся вопросы разработки эффективного механизма регулирования сферы страхования, важнейшее место в котором отводится системе внутреннего контроля деятельности страховых организаций, построенной на принципах риск-ориентированного подхода в соответствии co стандартами Solvency II, в целях ранней диагностики рисков.

Теоретической основой исследования выступают теории страхования, риск-менеджмента и конфликтно-компромисного управления, 
концепции и фундаментальные труды представителей различных школ экономической теории: А. Вагнер, А. Манэс, Гупка, Дж. Фон Нейман, О. Моргенштерн, К.Г. Воблый, В.Г. Галиля, Л.К. Васюкова, Е.В. Коломин, Л.В. Донцова, М.М. Шарамко, Н.Н. Масюк, М.А. Бушуева, Н.А. Мосолова, О.С. Сухарев, Р.Т. Юлдашев и Л.И. Цветкова. Несмотря на то, что в трудах данных авторов уделено значительное внимание исследуемой теме, теоретическое осмысление роли системы контроля в страховых организациях требует дополнительного исследования и научного осмысления, с целью внесение предложений по выходу страхования из кризисного состояния.

Основополагающей гипотезой данного исследования является предположение о том, что формирование трехуровневой системы внутреннего контроля, построенной на принципах риск-ориентированного подхода в соответствии со стандартами Solvency II, позволят осуществлять раннюю диагностику рисков потери финансовой устойчивости и платежеспособности страховых организации.

\section{Методология исследования}

Статья подготовлена на основе проведения кабинетных исследований, информация собрана посредством качественных методов сбора данных, а именно сравнительного анализа, факторного анализа, формализованного контент-анализа. Информационную базу для сбора данных составили труды отечественных и зарубежных исследователей в области разработки методического обеспечения системы внутреннего контроля в страховых организациях. В ходе исследования собраны статистические и аналитические данные Федеральной службы по финансовым рынкам, отчетные и аналитические материалы других государственных учреждений и общественных организаций, работающих на страховом рынке России.

\section{Результаты анализа}

Объективные предпосылки создания системы внутреннего контроля обусловлены особенностями нового этапа развития страхового рынка России и связаны с преодолением последствий эконо- 
мического кризиса 2008 года, вступлением России во Всемирную торговую организацию, изменением российского страхового законодательства. Однако на сегодняшний день система внутреннего контроля страховых организаций на российском рынке находится в стадии становления. Ключевые показатели развития рынка страхования представлены в таблице 1.

Таблийа 1.

Ключевые показатели развития рынка страхования России

\begin{tabular}{|l|c|c|c|c|c|c|c|}
\hline \multicolumn{1}{|c|}{ Показатели } & 2012 & 2013 & 2014 & 2015 & 2016 & 2017 & 2018 \\
\hline Коэффициент выплат, \% & 45,66 & 46,52 & 47,81 & 49,74 & 42,84 & 39,86 & 35,35 \\
\hline $\begin{array}{l}\text { Численность страховых органи- } \\
\text { заций на конец года, ед. }\end{array}$ & 445 & 407 & 391 & 346 & 256 & 225 & 196 \\
\hline $\begin{array}{l}\text { Численность перестраховочных } \\
\text { компаний на конец года,ед. }\end{array}$ & 33 & 27 & 25 & 78 & 57 & 53 & 46 \\
\hline Концентрация рынка ТОП-10, \% & 57,09 & 56,82 & 59,04 & 65,62 & 64,63 & 65,3 & 65,38 \\
\hline Доля отозванных лицензий, \% & 2,47 & 2,46 & 2,30 & 7,23 & 5,08 & 3,11 & 4,08 \\
\hline
\end{tabular}

Источник: составлено автором по [9]

Предпосылкой возникновения и развития страховых экономических отношений являются убытки, возникающие вследствие опасных случайных событий, имеющих различную природу: несчастные случаи, стихийные бедствия, аварии, катастрофы.

Статистические данные, свидетельствующие о результатах работы российских страховых компаний, показывают некоторый рост объёма собираемой страховой премии по итогам работы за 2018 г. в сравнении с аналогичным периодом прошлого года - 115,72\% (1479 млрд рублей). При этом объём произведённых страховых выплат остался практически на уровне прошлого года - 523 млрд рублей в 2018 г. и 509,7 за 2017 г. [8, 9]. Снижение объёма предоставленной страховщиками материальной формы страховой защиты вовсе не свидетельствует о снижении рисков хозяйствующих субъектов или рисков жизнедеятельности граждан.

Данная статистика свидетельствует о кризисном состоянии страхового рынка России вследствие невыполнения страхованием контрольной функции, вследствие чего о необходимости внедрение 
эффективной системы внутреннего контроля рисков нарушения платёжеспособности, и тем более, рисков нарушения ликвидности, что поспособствует их нейтрализации на начальной стадии.

Очевидно, что одной из причин кризисного развития рынка является неудовлетворённость страхователей, как покупателей страхового товара, его качеством. Кроме того, у страхователей нет доверия к страховым компаниям, как финансово устойчивому и платёжеспособному институту, способному эффективно управлять рисками своих клиентов. Страхование, как категория финансов, несёт в себе две основные функции финансов - распределительную и контрольную [7]. В целях повышения доверия страхователей к страховщикам необходимо совершенствовать контрольную функцию страхования.

Вступая в страховые отношения, граждане или хозяйствующие субъекты, реализуют свою потребность в получении защиты от убытков, которые могут принести опасные случайности.

Страховщик, основной функцией в этих отношениях которого, является аккумулирующая функция по формированию страхового фонда, временно управляет страховыми резервами, пока не истекли сроки действия страховых контактов и не произведены страховые выплаты по всем заявленным убыткам [10]. Страховые премии, уплаченные по страховым контрактам и аккумулированные страховщиком в страховой фонд, являются коллективной собственностью страхователей. Государство в Законе «Об организации страхового дела в Российской Федерации» определяет исключительное назначение страховых резервов для производства страховых выплат, и подтверждает факт, что страховые резервы не подлежат изъятию в федеральный бюджет и бюджеты иных уровней [1]. Таким образом, контрольная функция страхования выражается как контроль за строго целевым формированием и использованием средств страхового фонда. Система эффективного, прежде всего внешнего (государственного), контроля деятельности страховщиков могла бы способствовать формированию доверия страхователей и уверенности в приобретенных страховых продуктах. 
Основной проблемой осуществления государственного надзора за деятельностью субъектов страхового рынка, делающей данный контроль неэффективным, является в основном его последующий характер. До настоящего времени надзорные действия регулятора сводятся к выявлению уже возникших нарушений финансовой устойчивости страховщиков и применение мер дисциплинарного воздействия к ним. Меры воздействия на страховые компании также крайне примитивны - ограничение, приостановка или отзыв лицензии у страховщика на право ведения страховой деятельности. Действующая система страхового надзора не осуществляет предупредительно-профилактическую функцию, и соответственно не выступает в качестве инструмента, осуществляющего превентивный контроль финансовых рисков участников страхового рынка. В связи с этим происходит рост количества отзыва лицензий на право осуществления страховой деятельности, а именно у 27 компаний за 2018 г., у 24 - за 2017 г. и у 73 организаций за 2016 г. [8, 9]. Наиболее распространённой причиной отзыва лицензий является нарушение платёжеспособности страховщика, несоответствие активов страховой компании принятым обязательствам.

Данная статистика свидетельствует о том, что в страховых компаниях необходимо внедрение эффективной системы внутреннего контроля рисков нарушения платёжеспособности, и тем более, рисков нарушения ликвидности, что поспособствует их нейтрализации на начальной стадии.

Успешное функционирование страховой организации невозможно без обеспечения эффективного контроля, позволяющего менеджменту компании получать необходимую и достоверную информацию для принятия управленческих решений. Для оценки финансовой устойчивости страховой организации система внутреннего контроля должна осуществлять постоянный мониторинг соответствие параметров и требований, на основе которых разработана модель системы внутреннего контроля и аудита страховых организаций, направленная на превентивную диагностику рисков страховщика: 
1. Наличие лицензии на право осуществления страховой деятельности.

2. Проверка достаточности и соответствия отчетности страховых организаций, которая сдается в Министерство Финансов.

3. Требования к минимальному размеру капитала (MCR), который страховщики и перестраховщики должны резервировать.

4. Требования к капиталу для обеспечения платёжеспособности (SCR).

5. Соответствие показателей финансовой устойчивости и платежеспособности страховой организации пруденциальным нормативам.

6. Требования к качеству и соответствию активов страховой организации.

7. Комплексный учет и анализ собственных рисков страховой организации.

Помимо этого, для выхода рынка страховых услуг из кризисного состояния необходимо совершенствовать процесс стратегического и финансового управления организаций, путем внедрения конфликтно-компромиссной методологии принятия управленческих решений. Конфликтно-компромиссное управление, как и теория ограничений Голдратта, оперирует понятием «конфликт», который рассматривается как кульминация развития противоречий в системе, возникающих вследствие управленческих дисфункций, и является движущей силой развития системы [4]. Для разрешения конфликта необходимо принять некое компромиссное решение.

В ходе разрешения компромисса стороны могут также достичь консенсуса. На сегодняшний день у страховщиков возникает множество противоречивых ситуаций, возникающих вследствие неверно принятых управленческих решений, как участниками страховых отношений, так и регулятором страхового рынка. Модель экономических отношений «страховщик - страхователь» должна строиться на поиске локальных компромиссов, позволяющих разрешить возникающие управленческие дисфункции посредством использования методологии конфликтно-компромиссного управления [1].

Также проблема неэффективности системы государственного надзора за финансовой устойчивостью и платежеспособностью страховых компаний проявляется в подходе к осуществлению дан- 
ной функции. В настоящее время контроль деятельности крупных компаний, которые порождают системные кросс-секторальные риски, способные в свою очередь привести к конфликту интересов значительного числа участников финансового рынка, и небольших региональных страховщиков осуществляется по одной методике, и проверка происходит по одним показателям. Остро встает проблема последующего контроля платежеспособности страховщиков. Вследствие чего целесообразным является введение автоматического мониторинга и обработки данных о финансовых показателях деятельности компаний на цифровой платформе. В качестве примера эффективной автоматизированной системы контроля можно привести систему онлайн обработки данных о налогоплательщиках, применяемую Федеральной налоговой службой.

Также необходимость создания и внедрения автоматизированной системы внутреннего контроля обуславливается внедрением системы «Маркетплейс», которая является электронным каналом реализации финансовых продуктов, базирующимся на принципах гарантирования прав и доступности финансовых услуг потребителям, разработанной Банком России совместно с участниками рынка. В связи с тем, что ЦБ предлагает страхователю приобретение страховых продуктов у финансово устойчивых страховых организаций, которые будут способны выполнить свои обязательства перед страховщиком, появляется острая необходимость в разработке системы внутреннего контроля страховщика, которая осуществляла бы превентивную диагностику финансовой устойчивости страховой компании, и посредством которой определялся бы перечень финансово устойчивых компаний, которые будут предлагать свои продукты в системе «Маркетплейс».

\section{Обсуждение полученных результатов}

Результаты исследования показали, что на сегодняшний день рынок страховых услуг переживает период кризиса, страхователи не доверяют страховым компаниям управление рисками по причине значительной вероятности того, что страховщик не сможет выполнить обязательства. Это свидетельствует о функционировании неэффективной системы внутреннего контроля и аудита страховых организаций. 
В ходе проведенного анализа, была подтверждена гипотеза исследования. Страховой рынок нуждается во внедрении эффективной системы внутреннего контроля, которая будет осуществлять мониторинг показателей финансовой устойчивости страховой организации и соответствие их пруденциальным нормативам, характеризующим достаточность собственного капитала и финансовую устойчивость страховой организации. При несоответствии показателей пруденциальным нормативам система внутреннего контроля должна сигнализировать об этом, тем самым осуществляя превентивную диагностику риска потери платежеспособности страховой организации, который может привести к неспособности страховщика выполнить свои обязательства.

\section{Заключение}

Исходя из всего вышесказанного, можно сделать вывод, что в настоящее время рынок страховых услуг находится в кризисном состоянии. Вследствие чего необходимо создание эффективной системы внутреннего контроля страховых организаций, в связи, с чем следует на основе вышеупомянутых требований и параметров разработать и внедрить автоматизированную систему контроля финансовой устойчивости и платежеспособности страховщиков, которая при несоответствии показателей пруденциальным нормативам оценки рисков, автоматически диагностировала и сигнализировала бы о существующих проблемах, что позволило бы страховой компании выйти из кризисной ситуации.

\section{Список литературы}

1. Об организации страхового дела в Российской Федерации [Электронный ресурс]: федеральный закон от 27.11.1992 г. № 4015-1-Ф3: принят Гос. Думой 27.11.1992 г.: (ред. от 28.11.2018 г.). Режим доступа : компьютерные сети ДВФУ. БД КонсультантПлюс.

2. О порядке осуществления мониторинга деятельности страховщиков [Электронный ресурс]: указание Банка России от 18.01.2016 г. № 3935У. Режим доступа : компьютерные сети ДВФУ. БД КонсультантПлюс.

3. Васюкова Л.К. Конфликтно-компромиссная методология разрешения противоречий участников страхового рынка / Л.К. Васюкова, Н.Н. Ма- 
сюк, М.А. Бушуева, Н.А. Мосолова, О.В. Козьминых // Вектор науки ТГУ. Серия: Экономика и управление. 2015. № 4 (23). С. 19-22.

4. Гвозденко А.А. Страхование. М.: ТК Велби, Изд-во Проспект, 2016. $464 \mathrm{c.}$

5. Гомелля В.Б. Очерки экономической теории страхования / Под ред. Е.В. Коломина. М.: АНКИЛ, 2016. 352 с.

6. Гущин А. В ожидании пруденциального надзора [Электронный ресурс] // Рейтинговое агентство «Эксперт РА». Режим доступа: http:// www.raexpert.ru/press/articles/risk_2016.

7. Давыдов С.А. Социология: конспект лекций. М.: Изд-во «Эксмо», 2008. $160 \mathrm{c}$.

8. Никитченко Ю.А. Системы внутреннего контроля страховщиков как элемент государственного финансового контроля устойчивого развития страхового рынка / Ю.А. Никитченко, Л.К. Васюкова // Известия ДВФУ. Экономика и управление. 2019. № 1. С. 123-131.

9. Пешкова Т.Ю. Управление рисками, внутренний контроль и внутренний аудит страховых организаций в системе страхового надзора Канады // Финансовая аналитика: проблемы и решения. 2013. № 42(180). С. 48-56.

10. Статистические данные об итогах работы страхового рынка [Электронный ресурс] // Официальный сайт Центрального Банка России. Режим доступа: http://cbr.ru/finmarkets/?PrtId=sv_insurance.

11. Статистические данные об итогах работы страхового рынка [Электронный ресурс] // Официальный сайт ЗАО Медиа-Информационная Группа «Страхование сегодня» (МИГ). Режим доступа: http:// www.insur-info.ru/statistics/analytics.

12.Fung D.W.H., Jou D., Shao A.J. et al, 2018. The China Risk-Oriented Solvency System: A Comparative Assessment with Other Risk-Based Supervisory Frameworks. Geneva Pap Risk Insur Issues Pract 43: 1636. Date Views 17.03.2019 https://doi.org/10.1057/s41288-017-0046-3.

13. Hofmann A., Neumann J.K. \& Pooser, D, 2018. Plea for Uniform Regulation and Challenges of Implementing the New Insurance Distribution Directive. Geneva Pap Risk Insur Issues Pract, 43: 740-769. Date Views 15.03.2019 https://doi.org/10.1057/s41288-018-0091-6. 
14. Masyuk N.N. Conflict-Compromise Methodology for Resolution of Conflict in Insurance Relations. / N.N. Masyuk, L.K. Vasyukova, M.A. Bushueva, N.A. Mosolova and O.V. Kozminykh // The Social Sciences, 2016. № 11: 6928-6932.

15. Swinkels L., Blitz, D., Hallerbach, W. et al, 2018. Equity Solvency Capital Requirements - What Institutional Regulation Can Learn from Private Investor Regulation. Geneva Pap Risk Insur Issues Pract, 43: 633652. Date Views15.03.2019 https://doi.org/10.1057/s41288-018-0086-3.

16. The Lima Declaration of Guidelines on Auditing Precepts (INTOSAI, 1977) [Электронный ресурс]. Режим доступа: www.ach.gov.ru.

\section{References}

1. Ob organizatsii strakhovogo dela v Rossiyskoy Federatsii [Elektronnyy resurs]: federal'nyy zakon ot 27.11.1992 g. № 4015-1-FZ : prinyat Gos. Dumoy 27.11.1992 g.: (red. ot 28.11.2018 g.) [On the organization of insurance in the Russian Federation [Electronic resource]: federal law of November 27, 1992 No. 4015-1-FZ: adopted by the State. The Duma on 11/27/1992: (as amended on 11/28/2018)]. ConsultantPlus.

2. O poryadke osushchestvleniya monitoringa deyatel'nosti strakhovshchikov [Elektronnyy resurs]: ukazanie Banka Rossii ot 18.01.2016 g. № 3935-U [On the procedure for monitoring the activities of insurers [Electronic resource]: Bank of Russia Ordinance No. 3935-U dated January 18, 2016]. ConsultantPlus.

3. Vasyukova L.K., Masyuk N.N., Bushueva M.A., Mosolova N.A., Koz'minyk O.V. Vektor nauki TGU. Seriya: Ekonomika i upravlenie [Vector of science of TSU. Series: Economics and Management]. 2015. No. 4 (23). S. 19-22.

4. Gvozdenko A.A. Strakhovanie [Insurance]. M.: TC Velby, Prospect Publishing House, $2016.446 \mathrm{p}$.

5. Gomellya V.B. Ocherki ekonomicheskoy teorii strakhovaniya [Essays on the economic theory of insurance] / ed. E.V. Kolomin. M.: ANKIL, $2016.352 \mathrm{~s}$.

6. Gushchin A. V ozhidanii prudentsial'nogo nadzora [In anticipation of prudential supervision]. Reytingovoe agentstvo «Ekspert RA». http:// www.raexpert.ru/press/articles/risk_2016. 
7. Davydov S.A. Sotsiologiya: konspekt lektsiy [Sociology: lecture notes]. M.: Eksmo Publishing House, 2008.160 p.

8. Nikitchenko Yu.A., Vasyukova L.K. Sistemy vnutrennego kontrolya strakhovshchikov kak element gosudarstvennogo finansovogo kontrolya ustoychivogo razvitiya strakhovogo rynka [Systems of internal control of insurers as an element of state financial control of sustainable development of the insurance market]. Izvestiya DVFU. Ekonomika i upravlenie. 2019. No 1, pp. 123-131.

9. Peshkova T.Yu. Upravlenie riskami, vnutrenniy kontrol' i vnutrenniy audit strakhovykh organizatsiy v sisteme strakhovogo nadzora Kanady [Risk management, internal control and internal audit of insurance organizations in the Canadian insurance supervision system]. Finansovaya analitika: problemy i resheniya. 2013. No. 42 (180), pp. 48-56.

10. Statisticheskie dannye ob itogakh raboty strakhovogo rynka [Statistical data on the results of the insurance market]. Ofitsial'nyy sayt Tsentral'nogo Banka Rossii [Official website of the Central Bank of Russia]. http:// cbr.ru/finmarkets/?PrtId=sv_insurance.

11. Statisticheskie dannye ob itogakh raboty strakhovogo rynka [Statistical data on the results of the insurance market]. Ofitsial'nyy sayt ZAO Media-Informatsionnaya Gruppa «Strakhovanie segodnya» (MIG) [Official site of CJSC Media-Information Group "Insurance Today” (MIG)]. http://www.insur-info.ru/statistics/analytics.

12.Fung D.W.H., Jou D., Shao A.J. et al, 2018. The China Risk-Oriented Solvency System: A Comparative Assessment with Other Risk-Based Supervisory Frameworks. Geneva Pap Risk Insur Issues Pract 43: 1636. Date Views 03/17/2019 https://doi.org/10.1057/s41288-017-0046-3.

13. Hofmann A., Neumann J.K. \& Pooser, D, 2018. Plea for Uniform Regulation and Challenges of Implementing the New Insurance Distribution Directive. Geneva Pap Risk Insur Issues Pract, 43: 740-769. Date Views 03/15/2019 https://doi.org/10.1057/s41288-018-0091-6.

14. Masyuk N.N., Vasyukova L.K., Bushueva M.A., Mosolova N.A., Kozminykh O.V. Conflict-Compromise Methodology for Resolution of Conflict in Insurance Relations. The Social Sciences, 2016. No. 11: 6928-6932. 
15. Swinkels L., Blitz, D., Hallerbach, W. et al, 2018. Equity Solvency Capital Requirements - What Institutional Regulation Can Learn from Private Investor Regulation. Geneva Pap Risk Insur Issues Pract, 43: 633-652. Date Views 03/15/2019. https://doi.org/10.1057/s41288-018-0086-3.

16. The Lima Declaration of Guidelines on Auditing Precepts (INTOSAI, 1977) [Electronic resource]. Access mode: www.ach.gov.ru.

\section{ДАННЫЕ ОБ АВТОРАХ}

Никитченко Юлия Андреевна, магистрант образовательной программы образовательной программы «Финансы», кафедра «Финансы и кредит», Школа экономики и менеджмента Дальневосточный федеральный университет о-в Русский, кампус ДВФУ, корпус G, г. Владивосток, 690922, Российская Федерачия nikitchenko_ia@students.dvfu.ru

Васюкова Людмила Константиновна, кандидат экономических наук, доцент, доцент кафедры «Финансы и кредит», Школа экономики и менеджмента

Дальневосточный федеральный университет о-в Русский, кампус ДВФУ, корпус G, г. Владивосток, 690922, Российская Федеращия vasyukova.lk@dvfu.ru

\section{DATA ABOUT THE AUTHORS}

Nikithenko Julia Andreevna, Master Student of the Educational Program «Finance», the Department «Finance and Credit», School of Economics and Management Far Eastern Federal University building G, FEFU campus, Russian Island, Vladivostok, 690922, Russian Federation nikitchenko_ia@students.dvfu.ru SPIN-code: 3117-6842 ORCID: 0000-0001-8482-2455 
Vasyukova Lyudmila Konstantinovna, Candidate of Economic Sciences, Associate Professor, Associate Professor of the Department «Finance and Credit», School of Economics and Management Far Eastern Federal University

building G, FEFU campus, Russian Island, Vladivostok, 690922, Russian Federation

vasyukova.lk@dvfu.ru

ORCID: 0000-0003-0934-8399

SPIN-code: 7062-0450 